\title{
Mandibular Ameloblastoma in an Elderly Patient: A Case Report
}

\author{
Kokoro Nagata, Kasumi Shimizu, Chu Sato, Hiroshi Morita, \\ Yoshihiro Watanabe, and Toshiro Tagawa \\ Departments of Oral and Maxillofacial Surgery, and Clinical Sciences, Medical Life Science Mie University Graduate School of Medicine, \\ 2-174 Edobashi, Tsu, Mie 514-8507, Japan \\ Correspondence should be addressed to Kokoro Nagata; kokoro-m@clin.medic.mie-u.ac.jp
}

Received 8 January 2013; Accepted 5 February 2013

Academic Editors: M. A. Polack and M. O. Sayin

Copyright (C) 2013 Kokoro Nagata et al. This is an open access article distributed under the Creative Commons Attribution License, which permits unrestricted use, distribution, and reproduction in any medium, provided the original work is properly cited.

Ameloblastomas frequently occur in relatively young people, but are rarely seen in people aged 80 years or older. We report a case of mandibular ameloblastoma in an elderly patient with a review of the literature. The patient was a 82-year-old man who noticed swelling of the gingiva approximately 2 weeks prior to his initial visit. Computed tomography showed a radiolucent area with little radiopacity. Internal uniformity was observed at the site, with thinning of cortical bone which lacked continuity in some areas. The excision and curettage were performed under general anaesthesia. No recurrence has been observed 14 months after surgery.

\section{Introduction}

Among odontogenic tumours, ameloblastomas have the highest rate of occurrence after odontomas [1]. They are said to comprise between $10 \%$ and $50 \%$ of all odontogenic tumours [2-4]. The age group predilection peaks in the $20 \mathrm{~s}$ and 30s, with the average age being between 30 and 40 years, and the majority of cases occur in the 30 to 60 years age group [1, 2, 5-7]. Based on these figures, ameloblastomas are considered to be fairly rare in the elderly. We present a case of ameloblastoma in the mandible of an 82-year-old man and discuss the occurrence of this tumour in the elderly.

\section{Case Presentation}

An 82-year-old Japanese man presented with swelling of the gingival in the molar region of the left mandible. Approximately 2 weeks prior to the first visit, the patient noticed swelling of the gingiva, and panoramic X-rays were taken at a dental clinic. The images revealed radiolucent findings at the site, and the patient was referred to our facility for examination. The patient had a moderate physique and was well nourished, but he was taking medication for hypertension.

Intraoral findings showed that the upper and lower jaws were edentulous, with a relatively irregular border from the centre of the mandible to the gingiva of the molar region on the left side. Diffuse swelling and surface ulceration were observed. There was neither tenderness nor numbness of the lips (Figure 1).

Panoramic radiographs revealed a barely perceptible, polycystic radiolucent area with slightly irregular margins in the left molar region of the mandible (Figure 2).

Computed tomography showed a radiolucent area with little radiopacity. Internal uniformity was observed at the site, with thinning of cortical bone which lacked continuity in some areas (Figure 3). After 1 month, a biopsy and a needle aspiration were performed. Five millilitres of yellow-white content was aspirated. The results of bacteriological analysis were negative. Histopathological findings revealed that the squamous epithelium was accompanied by chronic inflammatory cell infiltration. Based on these findings, a diagnosis of benign tumor of the mandible was made, and after 2 months, excision and curettage were performed under general anaesthesia. The lesion partially adhered to the bone, and the surface of the peripheral bone was slightly rough. An inferior alveolar neurovascular bundle was also observed below the tumour, and this was preserved. After excision of the tumor in one piece, curettage was performed and the wound was left open. Seven months after surgery, there has been no recurrence of the tumour, and the patient is currently being monitored as an outpatient. 
TABLE 1: Intraosseous ameloblastoma.

\begin{tabular}{lccccccc}
\hline Year & Author & Sex & Age & Location & Pathological type & Treatment & Race \\
\hline 1986 & Ohyama et al. [8] & M & 82 & Maxilla & Follicular type & Excision (general anesthesia) \\
1991 & Iwata et al. [9] & F & 83 & Maxilla & Follicular type & Excision (general anesthesia) & Japanese \\
1998 & John et al. [10] & F & 80 & Maxilla & Plexiform type & Excision (general anesthesia) & Marginal resection \\
1998 & Lee et al. [11] & F & 83 & Mandible & Desmoplastic type & Asian \\
2004 & Koya et al. [12] & M & 81 & Mandible & Desmoplastic type & Marginal resection (general anesthesia) & Japanese \\
2010 & This case & M & 82 & Mandible & Follicular type & Excision and curettage (general anesthesia) & Japanese \\
\hline
\end{tabular}

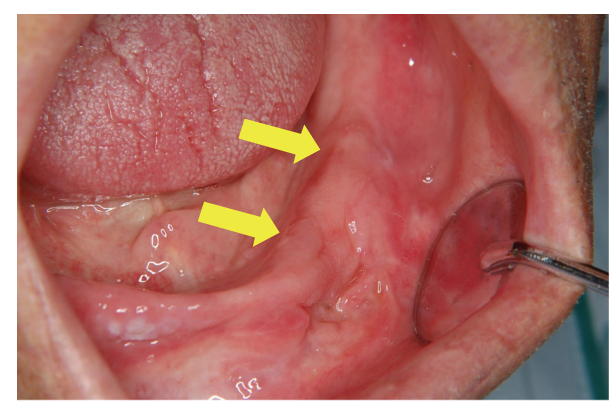

FIgURE 1: Intraoral findings at the first visit. The upper and lower jaws were edentulous, with a relatively irregular border from the centre of the mandible to the gingiva of the molar region on the left side. Diffuse swelling was observed, accompanied by surface ulceration.

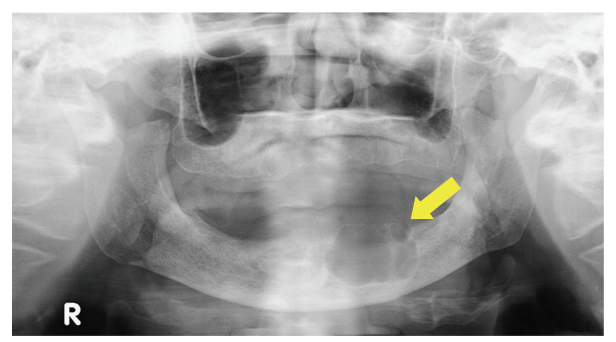

Figure 2: Panoramic X-ray view. A polycystic radiolucent area with an irregular margin can be seen in the molar region of the mandible on the left side.

The extracted tumour measured $3 \times 2.5 \mathrm{~cm}$ and was milky-white in colour, with a slightly rough surface. The transverse section was mostly cystoid, but solid portions were also observed (Figure 4). Histopathological diagnosis was follicular-type ameloblastoma. Haematoxylin-eosin staining revealed alveolar cell hyperplasia with a funicular structure in the fibrosing interstitial tissue, as well as a palisade arrangement (Figure 5).

\section{Discussion}

Ameloblastomas have a relatively high rate of occurrence and are seen across a wide spectrum of ages [1]. The peak occurrence rate is in the 20 s and 30 s and reports of these tumours in elderly patients are rare [2, 5-7]. A thorough search by the authors found only 11 reports cases of ameloblastoma

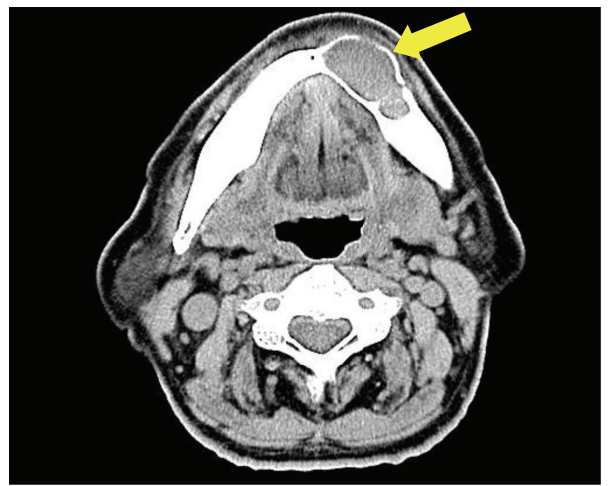

FIgURE 3: Computed tomography view. This shows thinning of peripheral bone was observed, with the bone lacking continuity in some areas.

worldwide in patients aged 80 or older between 1977 and 2010. In six of these cases, including the case reported here, the ameloblastoma was located in the centre of the jaw [8$12]$, and there were three cases each in the maxilla and the mandible. In terms of histological type, three cases were of the follicular type, two were desmoplastic, and one was plexiform (Table 1). The five remaining cases were peripheral ameloblastomas [13-17], two of which occurred in the maxilla, one in the mandible or gingiva, and two in the buccal mucous (Table 2). The ratio of men to women in these 11 cases was $4: 7$, although this may be related to the longer life expectancy of women than men. Of the 11 cases, eight cases were Japanese patients, one was of Asian ethnicity, one was African, and in one case the ethnicity was not noted. Reichart et al. categorised ameloblastoma patients into three ethnicities and found that the mean ages at the time of diagnosis were 28.7, 39.9, and 41.2 years for patients of African, Caucasian and Asian ethnicity, respectively [6]. The fact that the age at occurrence among Asian patients is higher may be because more than $80 \%$ of the cases in patients 80 years of age or older occur in Asians.

In reports by Philipsen et al. [18] and Wettan et al. [19], peripheral ameloblastoma comprises $1-10 \%$ of all ameloblastoma cases, but in our study of elderly patients, five of the 11 cases studied (45.5\%) were peripheral ameloblastomas. According to a 2005 classification by WHO, the mean age of occurrence for intraosseous ameloblastoma is 37 years, while the mean age of patients with peripheral ameloblastomas is 51 years, and $64 \%$ of all cases occur between 50 and 70 years of 
TABLE 2: Peripheral ameloblastoma.

\begin{tabular}{lcccccc}
\hline Year & Author & Sex & Age & Location & Treatment & Race \\
\hline 1977 & Frankel et al. [13] & F & 92 & Maxillary gingiva & Excision (general anesthesia) \\
1988 & Takeda et al. [14] & F & 89 & Mandibular gingiva & Excision and curettage (local anesthesia) & Japanese \\
1992 & Ohuchida et al. [15] & F & 81 & Maxillary gingiva & Excision (general anesthesia) & Japanese \\
2007 & Yamanishi et al. [16] & M & 80 & Buccal mucosa & Excision (general anesthesia) & Japanese \\
2009 & Isomura et al. [17] & F & 88 & Buccal mucosa & Excision (general anesthesia) & Japanese \\
\hline
\end{tabular}

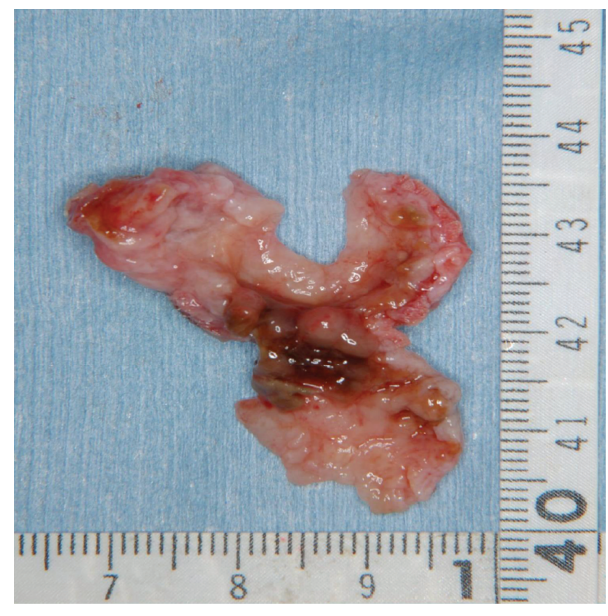

FIGURE 4: The excised tumor. It was milky-white in colour, with a slightly rough surface. The transverse section was largely cystoid, but solid portions were also observed.

age [1]. This advanced age may reflect the fact that the age of occurrence is higher for peripheral ameloblastomas. Based on these facts, intraosseous ameloblastomas in elderly patients, as in the case described here, are believed to be relatively rare. Moreover, it is possible that figures for peripheral ameloblastomas include those that occur as a result of alveolar bone being absorbed as a function of ageing, in which case the tumour remains in the soft tissue.

Among reported cases of intraosseous that were diagnosed preoperatively, there have been three cases, including the one described here, in which a benign tumour was suspected $[8,10]$ : one case of cyst [9], one case in which a clear diagnosis could not be made [11], and one case of malignant tumour [12]. When diagnosing ameloblastomas in elderly patients, there is frequently missing or defective dentition in the affected area, and there are no typical signs such as root absorption. Thus, it is important to differentiate patients with tumours from those with cystic diseases such as residual cysts.

A number of therapies are being investigated for the treatment of ameloblastomas, but in elderly patients, considering their overall physical condition and age, it is necessary to select a minimally invasive surgical approach. Even when the tumour was resected, resection was sometimes performed under local anaesthesia, due to the patient's overall physical condition and the need to preserve the function of the affected area [14] and cases in which the tumour was resected

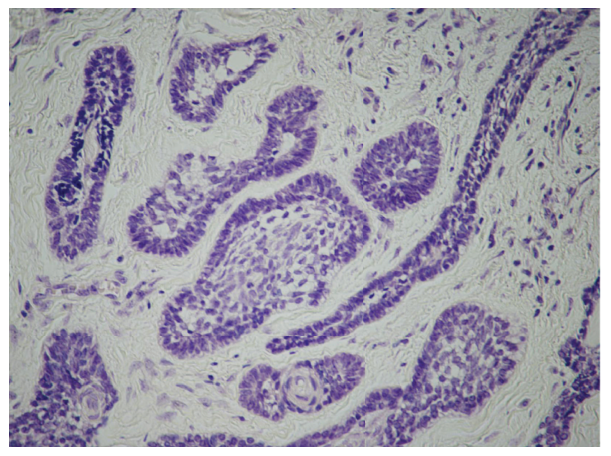

FIGURE 5: Histopathological findings. Alveolar cell hyperplasia with a funicular structure in the fibrosing interstitial tissue was observed, as well as a palisade arrangement (Haematoxylin and eosin staining, $\times 150)$.

to the greatest possible extent [9]. In the case described here, after a diagnosis of ameloblastoma was confirmed by intraoperative frozen section diagnosis, the tumour was extracted and curettage was performed. Repeat curettage would generally be performed after 6 months or 1 year, but instead the patient was monitored, due to his advanced age. The authors believe that ongoing, close monitoring will be necessary for this patient.

\section{References}

[1] D. G. Gardner, K. Heikinheimo, M. Shear, H. P. Philipsen, and H. Coleman, "Ameloblastomas," in World Health Organization Classification of Tumors. Pathology and Genetics of Head and Neck Tumors, L. Barnes, J. W. Eveson, P. Reichart, and D. Sidransky, Eds., pp. 296-300, IARC Press, Lyon, France, 2005.

[2] M. Takagi, Atlas of Oral Pathology, Bunkodo, Tokyo, Japan, 2004.

[3] T. D. Daley, G. P. Wysocki, and G. A. Pringle, "Relative incidence of odontogenic tumors and oral and jaw cysts in a Canadian population," Oral Surgery, Oral Medicine, Oral Pathology, vol. 77, no. 3, pp. 276-280, 1994.

[4] K. Kasahara, I. Kobayashi, T. Fujiwara et al., "Clinical Study of the odontogenic tumors," Journal of the Japan Stomatological Society, vol. 43, pp. 661-671, 1994.

[5] E. M. Robert and S. Diane, Oral and Maxillofacial Pathology, Quintessence Publishing, Hanover Park, Ill, USA, 2003.

[6] P. A. Reichart, H. P. Philipsen, and S. Sonner, "Ameloblastoma: Biological profile of 3677 cases," European Journal of Cancer B, vol. 31, no. 2, pp. 86-99, 1995. 
[7] D. G. Gardner, "Critique of the 1995 review by Reichart et al. of the biologic profile of 3677 ameloblastomas," Oral Oncology, vol. 35, no. 4, pp. 443-449, 1999.

[8] S. Ohyama, N. Koga, M. Koga et al., "Ameloblastoma of the maxilla: report of a case," Japanese Journal of Oral and Maxillofacial Surgery, vol. 32, pp. 434-440, 1986.

[9] M. Iwata, K. Nishijima, S. Takagi et al., "Ameloblastoma of the maxilla: report of four cases and review of the literature," Japanese Journal of Oral and Maxillofacial Surgery, vol. 37, pp. 1826-1834, 1991.

[10] G. John, K. L. Stewart, R. I. Steven, R. B. Julius, and P. S. Marshall, "Plexiform ameloblastoma involving the maxillary antrum," The New York State Dental Journal, vol. 64, pp. 34-36, 1998.

[11] C. Y. Lee, J. Lee, K. Hirata, and C. E. Tomich, "Desmoplastic variant of ameloblastoma in an 83-year-ald Asian female: report of a case with literature review," Hawaii Dental Journal, vol. 29, no. 3, pp. 12-24, 1998.

[12] E. Koya, M. Mihara, K. Nakashiro, S. Shintani, and H. Hamakawa, "A case of desmoplastic ameloblastoma in an elderly patient," Japanese Journal of Oral Diagnosis and Oral Medicine, vol. 17, pp. 58-61, 2004.

[13] K. A. Frankel, J. D. Smith, and L. S. Frankel, "Soft tissue ameloblastom in a 92-year-old woman," Archives of Otolaryngology, vol. 103, pp. 499-500, 1977.

[14] Y. Takeda, M. Kuroda, and A. Suzuki, "Ameloblastoma of mucosal origin," Acta Pathologica Japonica, vol. 38, no. 8, pp. 1053-1060, 1988.

[15] M. Ohuchida, S. Tanaka, J. Kusukawa, A. Nagata, T. Okina, and T. Kameyama, "A case of peripheral ameloblastoma arising in the maxilla," Japanese Journal of Oral and Maxillofacial Surgery, vol. 38, pp. 1437-1438, 1992.

[16] T. Yamanishi, S. Ando, T. Aikawa et al., "A case of extragingival peripheral ameloblasotoma in the buccal mucosa," Journal of Oral Pathology and Medicine, vol. 36, no. 3, pp. 184-186, 2007.

[17] E. T. Isomura, S. Ishimoto, T. Yamada, Y. Ono, and M. Kishino, "Case report of extragingival peripheral ameloblastoma in buccal mucosa," Oral Surgery, Oral Medicine, Oral Pathology, Oral Radiology and Endodontology, vol. 108, no. 4, pp. 577-579, 2009.

[18] H. P. Philipsen, P. A. Reichart, H. Nikai, T. Takata, and Y. Kudo, "Peripheral ameloblastoma: biological profile based on 160 cases from the literature," Oral Oncology, vol. 37, no. 1, pp. 17-27, 2001.

[19] H. L. Wettan, P. A. Patella, and P. D. Freedman, "Peripheral ameloblastoma: review of the literature and report of recurrence as severe dysplasia," Journal of Oral and Maxillofacial Surgery, vol. 59, no. 7, pp. 811-815, 2001. 


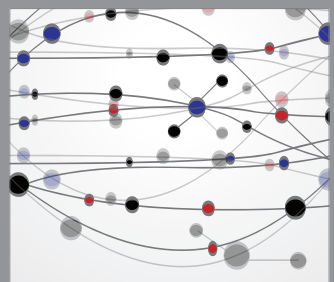

The Scientific World Journal
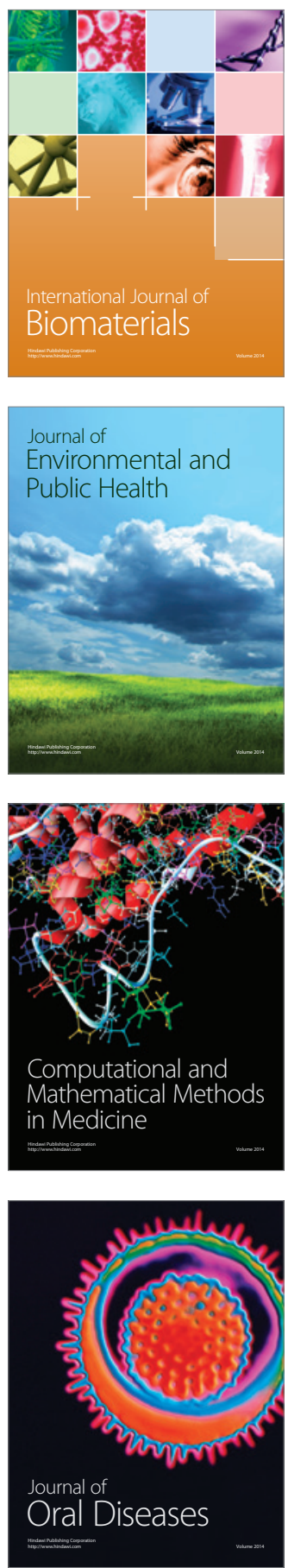
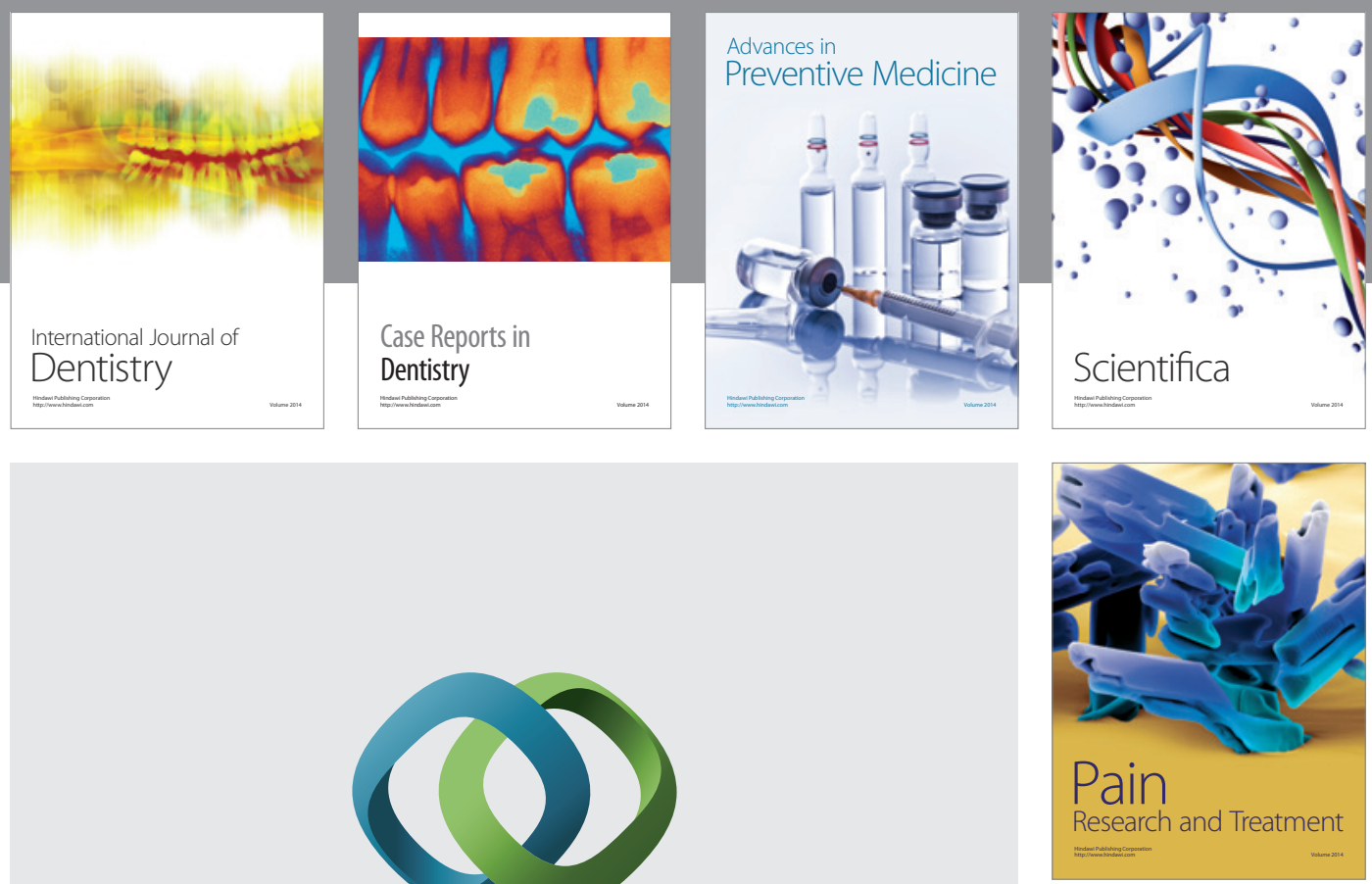

\section{Hindawi}

Submit your manuscripts at

http://www.hindawi.com
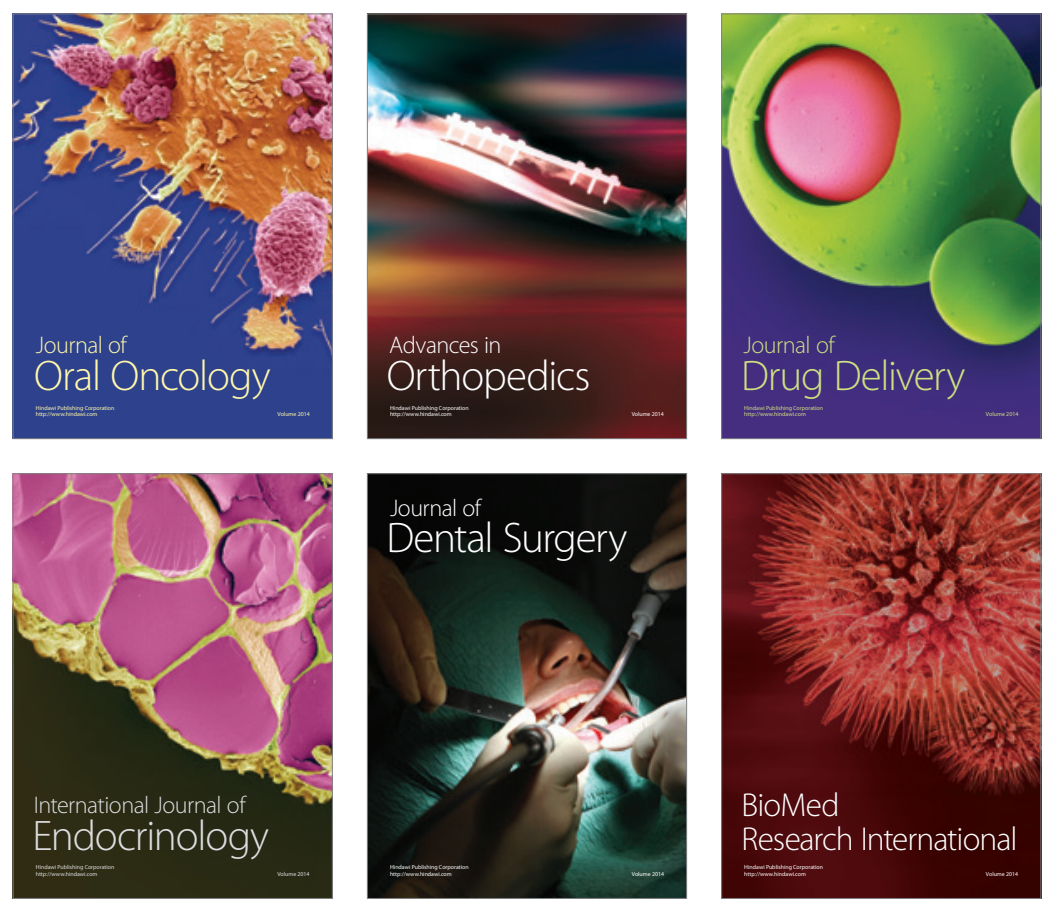

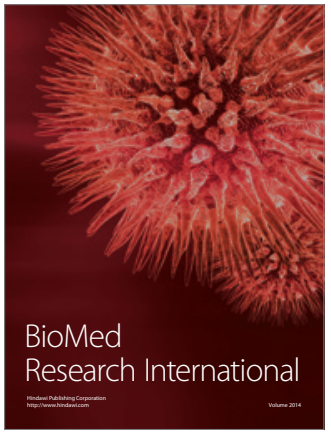

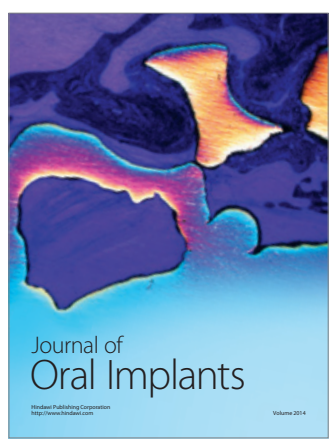
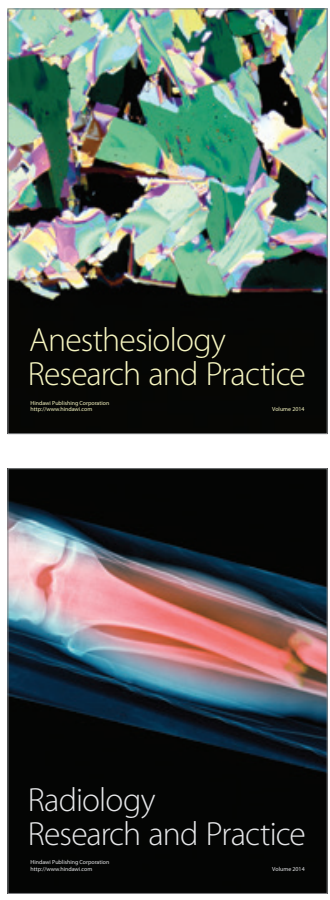